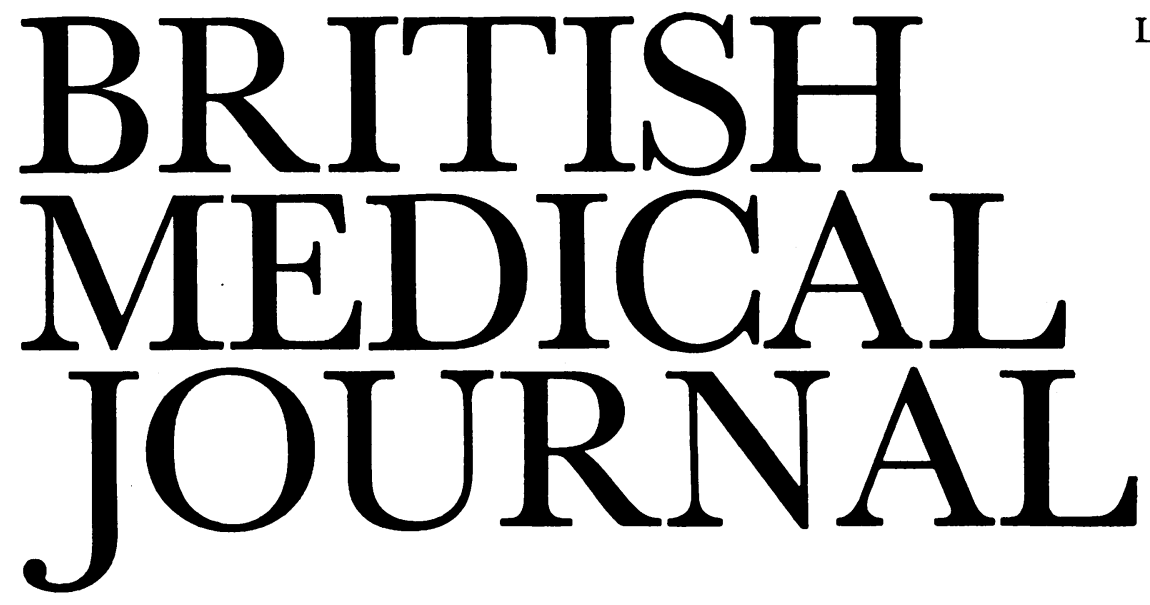

LONDON, SATURDAY 24 OCTOBER 1987

\title{
Alcohol, coffee, fat, and breast cancer
}

Nutritional and other dietary factors have been described as a "chronic source of both frustration and excitement to epidemiologists." The same could be said of breast cancer, an enigmatic disease for which basic concepts are continually being revised. For example, recent studies suggest that early theories about the protective effects of breast feeding and high parity (after allowing for age at first birth) may have been discarded prematurely. ${ }^{23} \mathrm{Or}$ again, despite theoretical grounds for predicting that cigarette smoking would reduce the risk of breast cancer ${ }^{4}$ the epidemiological evidence is unconvincing. ${ }^{56}$

The combination of diet and breast cancer has thus been a minefield for epidemiologists. The importance of nutritional factors is suggested by the observation that overweight women have a higher overall risk of breast cancer, although the reverse appears to be true before the menopause. ${ }^{78}$ For more than a decade attention has been focused on the idea that dietary fat might be important in breast cancer, but recent research has cast doubt on the fat hypothesis while pointing to a possible hazard of alcohol.

The first report linking alcohol and breast cancer was published in the United States in 1977. Williams and Horm found that women with breast cancer drank more alcohol than patients with other malignancies. ${ }^{9}$ Nearly 20 further studies have been reported, and most have shown an increased risk with moderate alcohol consumption. ${ }^{111}$ Several of these studies compared women with breast cancer with controls suffering from other diseases, and some of the controls might have been avoiding alcohol for health reasons. Another limitation of case-control studies is that recall of drinking habits might have been affected by the diagnosis of cancer, but three cohort studies in which alcohol consumption was recorded prospectively also showed an increased risk. ${ }^{12-14}$ One of these studies followed up about 90000 American nurses: the relative risk of breast cancer was 1.3 in nurses taking 5-14 $\mathrm{g}$ of alcohol a day and 1.6 in those drinking larger amounts. ${ }^{14}$

Such small relative risks are always difficult to interpret, but a causal relation would be of major public health importance because alcohol consumption is so common. Chance is not a plausible explanation for the association because of the consistency of published findings. Since most of the studies were not designed to examine the effect of alcohol the possibility of publication bias (through selective submission or publication of positive results) must be considered. The increased risk of breast cancer might have been caused by some other characteristic of regular drinkers, perhaps related to their social class, but adjustment for known risk factors, including dietary habits, ${ }^{14}$ did not eliminate the association. Hence a causal explanation must be seriously considered. Several biological mechanisms have been suggested but are speculative."

Concerns about another popular beverage, coffee, have been laid to rest. These arose from a report that avoiding coffee and other sources of methylxanthines led to regression of clinical fibrocystic disease of the breast, which is a risk factor for breast cancer. ${ }^{15}$ Several case-control studies have found no increased risk of breast cancer in women drinking coffee. ${ }^{16-18}$

The hypothesis that dietary fat may cause breast cancer has been a central theme of research for sound reasons. Firstly, abundant evidence from animal studies shows that mammary carcinogenesis is enhanced by high fat diets and inhibited by calorie restriction. ${ }^{19}$ Secondly, incidence and mortality rates for breast cancer in different countries are highly correlated with fat consumption-even after controlling for height, weight, and age at menarche. ${ }^{20}$ In Japan, where breast cancer is uncommon, a rapid increase in fat intake has been accompanied by a rise in the death rate from breast cancer. ${ }^{21}$

Yet studies of fat intake and breast cancer in individuals have produced conflicting results. ${ }^{22-24}$ One reason for this might be the small range of fat consumption in most of the populations studied. In Greece, however, where there is greater variability in diet, a recent case-control study showed no association of breast cancer with fat (while suggesting a protective effect of vegetables). ${ }^{25}$ Further evidence against the fat hypothesis came from the follow up study of American nurses. Using dietary data from a self administered questionnaire, Willett and others found no evidence of a positive relation between the risk of breast cancer and intake of total or saturated fat, linoleic acid, or cholesterol. ${ }^{26}$ Despite the well known advantages of prospective studies of individuals, this result is not conclusive. The follow up was only four years, so any effect of high fat consumption earlier in life would have been missed. The range of fat intakes was also modest, with women in the highest and lowest quintiles 
deriving an average respectively of $44 \%$ and $32 \%$ of calories from fat. Furthermore, although careful steps were taken to validate the dietary questionnaire, the inevitable imprecision of data derived from questionnaires was evident from the information provided.

The best evidence of any causal association would be provided by an intervention study. The United States National Cancer Institute will shortly decide whether to proceed with a large randomised trial to test the hypothesis that restricting dietary fat can reduce the incidence of breast cancer. ${ }^{27}$ The trial would include 32000 women aged 45 to 69 with risk factors for breast cancer. A pilot study has shown that a substantial reduction in fat intake (from an average of $39 \%$ of calories to $21 \%$ ) can be achieved and sustained for at least one year. Critics of the proposed trial, which would last a decade and cost around $\$ 100 \mathrm{~m}$, argue that the resources might be spent more effectively on observational studies or laboratory research. But the organisers believe that this may be the only way to settle the long standing debate about fat and breast cancer.

Professor of Preventive and Social Medicine and

D C G SKEGG

Director of the Hugh Adam Cancer Epidemiology Unit,

University of Otago,

Dunedin, New Zealand

1 Peto R. The preventability of cancer. In: Vessey MP, Gray M, eds. Cancer risks and prevention. Oxford: Oxford University Press, 1985:1-14.

Byers T, Graham S, Rzepka T, Marshall J. Lactation and breast cancer. Am $\mathcal{J}$ Epidemiol 1985;121:664-74.

3 Trichopoulos D, Hsieh C, MacMahon B, et al. Age at any birth and breast cancer risk. Int f Cancer 1983;31:701-4.

4 Baron JA. Smoking and estrogen-related disease. Am f Epidemiol 1984;119:9-22.
5 Baron JA, Byers T, Greenberg ER, Cummings KM, Swanson M. Cigarette smoking in women with cancers of the breast and reproductive organs. $\mathcal{F}$ Natl Cancer Inst 1986;77:677-80.

6 O'Connell DL, Hulka BS, Chambless LE, Wilkinson WE, Deubner DC. Cigarette smoking, lcohol consumption, and breast cancer risk. $\mathcal{F}$ Natl Cancer Inst 1987;78:229-34.

7 Lubin F, Ruder AM, Wax Y, Modan B. Overweight and changes in weight throughout adult life $C$ in breast cancer etiology. Am $\mathcal{F}$ Epidemiol 1985;122:579-88.

8 Willett WC, Browne ML, Bain C, et al. Relative weight and risk of breast cancer among

Williams RR, Horm JW. Association of cancer sites with tobacco and alcohol consumption and 70 socioeconomic status of patients: interview study from the Third National Cancer Survey. \& 7 Natl Cancer Inst 1977;58:525-47.

10 Graham S. Alcohol and breast cancer. N Engl F Med 1987:316:1211-3.

11 Harvey EB, Schairer C, Brinton LA, Hoover RN, Fraumeni JF. Alcohol consumption and breast 2 cancer. $\mathcal{F}$ Natl Cancer Inst 1987;78:657-61.

12 Hiatt RA, Bawol RD. Alcoholic beverage consumption and breast cancer incidence. $A m \mathcal{F}$ Epidemiol 1984;120:676-83.

13 Schatzkin A, Jones DY, Hoover RN, et al. Alcohol consumption and breast cancer in the epidemiologic follow-up study of the first National Health and Nutrition Examination Survey. N Engl f Med 1987;316:1169-73.

14 Willett WC, Stampfer MJ, Colditz GA, Rosner BA, Hennekens CH, Speizer FE. Moderate alcohol consumption and the risk of breast cancer. $N$ Engl f Med 1987;316:1174-80.

15 Minton JP, Foecking MK, Webster DJT, Matthews RH. Caffeine, cyclic nucleotides, and breast disease. Surgery 1979;86:105-8.

16 Lubin F, Ron E, Wax Y, Modan B. Coffee and methylxanthines and breast cancer: a case-control study. F Natl Cancer Inst 1985;74:569-73.

17 Rosenberg L, Miller DR, Helmrich SP, et al. Breast cancer and the consumption of coffee. $A m \mathcal{J}$ Epidemiol 1985;122:391-9.

18 La Vecchia C, Talamini R, Decarli A, Franceschi S, Parazzini F, Tognoni G. Coffee consumption and the risk of breast cancer. Surgery 1986;100:477-81.

19 National Research Council. Diet, nutrition, and cancer. Washington, DC: National Academy Press, 1982:83-6.

20 Gray GE, Pike MC, Henderson BE. Breast-cancer incidence and mortality rates in different countries in relation to known risk factors and dietary practices. $\mathrm{Br} \mathcal{F}$ Cancer 1979;39:1-7.

21 Hirayama T. Diet and cancer. Nutr Cancer 1979;1:67-81.

22 Armstrong BK, Mann JI. Diet. In: Vessey MP, Gray M, eds. Cancer risks and prevention. Oxford: Oxford University Press, 1985:68-98.

23 Lubin F, Wax Y, Modan B. Role of fat, animal protein, and dietary fiber in breast cancer etiology: o a case-control study. F Natl Cancer Inst 1986;77:605-12.

24 Hirohata T, Nomura AMY, Hankin JH, Kolonel LN, Lee J. An epidemiologic study on the association between diet and breast cancer. $\mathcal{F}$ Natl Cancer Inst 1987;78:595-600.

25 Katsouyanni K, Trichopoulos D, Boyle P, et al. Diet and breast cancer: a case-control study in 0 Greece. Int f Cancer 1986;38:815-20.

26 Willett WC, Stampfer MJ, Colditz GA, Rosner BA, Hennekens CH, Speizer FE. Dietary fat and $N$ the risk of breast cancer. $N$ Engl $\mathcal{F}$ Med 1987;316:22-8.

27 Women's Health Trial Steering Committee. The Women's Health Trial: a randomized trial to prevent breast cancer incidence with a low fat diet. Abstracts for the International Epidemiological Association, XI Scientific Meeting. Helsinki: International Epidemiological Association, 1987:262-3. 